\section{Genome Size Estimates and Chromosome Numbers of Callicarpa L. (Lamiaceae)}

\author{
Ryan N. Contreras ${ }^{1,3}$ \\ Department of Horticulture, Oregon State University, 4017 Agricultural and \\ Life Sciences Building, Corvallis, OR 97331-7304
}

John M. Ruter ${ }^{2}$

Department of Horticulture, The University of Georgia, Tifton Campus, Tifton, GA 31793-0748

\section{Additional index words. beautyberry, cytology, flow cytometry}

\begin{abstract}
Genome size estimates and chromosome number information can be useful for studying the evolution or taxonomy of a group and also can be useful for plant breeders in predicting cross-compatibility. Callicarpa $\mathrm{L}$. is a group of $\approx 140$ species with nearly worldwide distribution. There are no estimates of genome size in the literature and the information on chromosome numbers is limited. Genome size estimates based on flow cytometry are reported here for 16 accessions of Callicarpa comprising 14 species in addition to chromosome counts on six species. Chromosome counts were conducted by staining meristematic cells of roots tips using modified carbol fuchsin. Holoploid genome size estimates ranged from $1.34 \mathrm{pg}$ to $3.48 \mathrm{pg}$ with a mean of $1.74 \mathrm{pg}$. Two tetraploids $(2 n=4 x=68 ; C$. salicifolia P'ei \& W. Z. Fang and $C$. macrophylla Vahl GEN09-0081) were identified based on holoploid genome size and confirmed by chromosome counts. There was little variation among species for monoploid genome size. $1 \mathrm{Cx}$-values ranged from $0.67 \mathrm{pg}$ to $0.88 \mathrm{pg}$ with a mean of $0.77 \mathrm{pg}$. Chromosome counts for six species revealed a base chromosome number of $x=17$. Callicarpa chejuensis Y. H. Chung \& H. Kim, $C$. japonica Thunb. 'Leucocarpa', $C$. longissima Merr., and $C$. rubella Lindl. were confirmed as diploids $(2 n=2 x=34)$. Cytology supported flow cytometry data that $C$. salicifolia and $C$. macrophylla GEN09-0081 were tetraploids. The two accessions of $C$. macrophylla included in the study were found to be of different ploidy levels. The presence of two ploidy levels among and within species indicates that polyploidization events have occurred in the genus.
\end{abstract}

Callicarpa is composed of $\approx 140$ species found in Asia, Africa, Australia, and North and South America; however, most species are distributed in tropical and subtropical Asia (Shou-liang and Gilbert, 1994). Centers of diversity have been identified as the Philippine Islands for Old World species and Cuba for New World species, the former comprising a much larger group (Moldenke, 1936). Callicarpa was previously placed in the Verbenaceae; however, it was recently transferred into Lamiaceae along with sev-

Received for publication 10 Jan. 2011. Accepted for publication 14 Feb. 2011.

We thank Nancy Hand for technical assistance and Tom Ranney and Peggy Ozias-Akins for the use of laboratory facilities and equipment. We also thank Denny Werner (previous Director JC Raulston Arboretum, Raleigh, NC), F. Todd Lasseigne (Paul J. Ciener Botanical Garden, Kernersville, NC), Rick Crowder (Hawksridge Farms, Hickory, NC), and Ted Stephens (Nurseries Caroliniana, North Augusta, SC) for providing plant material. Finally, we thank three anonymous reviewers for their time in reviewing the manuscript and helpful comments.

${ }^{1}$ Assistant Professor.

${ }^{2}$ Professor.

${ }^{3}$ To whom reprint requests should be addressed; e-mail contrery@hort.oregonstate.edu. eral other genera (Cantino, 1992; Harley et al., 2004). Most species are shrubs, but there are also tree and subscandent members of the genus (Moldenke, 1936). Leaves are typically decussate with axillary inflorescences that are most often cymose (Bramley, 2009; Moldenke, 1936). Beautyberries, as they are commonly referred, are grown primarily for their showy berry-like drupes produced in fall. However, species have been found to contain a number of compounds that have allelochemical activity (Cruz-Ortega et al., 2002), mosquito repellent properties (Cantrell et al., 2005), and act as cyanobactericides (Tellez et al., 2000). In addition to landscape use as an ornamental, Callicarpa spp. have been grown for use as cut stems for the florist's trade (Bir and Conner, 1997; Greer and Dole, 2009).

In recent years, there has been an increase in the number of genome size estimates available for both plants and animals (Bennett and Leitch, 2005; Gregory, 2005). For plants, there has been progress in documenting genome sizes for diverse groups (Bennett and Leitch, 2005) and angiosperms, in particular, have received much attention (Bennett and Leitch, 1995, 1997, 2005; Bennett et al., 2000). The Plant DNA C-values Database (Bennett and Leitch, 2005) currently contains data for 5150 species; however, no genome size estimates have been reported for Callicarpa.

Chromosome number has been a useful tool for researchers investigating evolutionary relationships (Guerra, 2008; Levin and Wilson, 1976), particularly at the generic level (Goldblatt, 2007). Chromosome number data complement genome size estimates by allowing calculation of chromosome size, which has been correlated with evolutionary age (Mehra and Bawa, 1972). Knowledge of chromosome number is also a useful tool for breeders (Fehr, 1991). Chromosome numbers can affect inbreeding depression and the potential for introgression of traits through interspecific hybridization, among other factors that can alter breeding strategy (Fehr, 1991). Unfortunately, relative to the number of species in the genus, the cytological information is sparse for Callicarpa.

The first beautyberry chromosome count reported was for $C$. japonica $(2 n=32)$ by Sugiura (1936), a count that appears to have been incorrectly cited numerous times. In the seminal compilation of Darlington and Wylie (1956), C. japonica is cited from Sugiura's (1936) publication; however, the count was reported as $2 n=16$, possibly because the original work cites the chromosome count using the haploid notation $(n=16)$. Another count attributed to Patermann (1938; see Darlington and Wylie, 1956) for C. japonica $(2 n=18)$ is not included in the bibliography and, therefore, should not be considered reliable. Lewis (1961) cited Darlington and Wylie (1956) and concluded that $2 n=18$ was the correct count for $C$. japonica and also provided the first account for $C$. americana $\mathrm{L}$. as $2 n=36$. Furthermore, he reported that $C$. americana was a tetraploid $(2 n=4 x=36)$, concluding that $x=9$ in Callicarpa. It seems that the erroneous citation of Sugiura's 1936 publication led to confusion regarding the base chromosome number in Callicarpa. Additional reports of chromosome numbers in Callicarpa are summarized in Table 1. Of note is the fact that multiple base chromosome numbers are reported $(x=16,17,18)$. Also, multiple chromosome numbers were reported for C. glabra Koidz. $(2 n=32,34$; Ono, 1975), C. macrophylla $(2 n=32,34$; Sharma and Mukhopadhyay, 1963), C. subpubescens Hook. \& Arn. $(2 n=30,34$; Ono, $1975)$, and C. tomentosa L. $(2 n=68,85$; Mehra and Bawa, 1969). These multiple base chromosome numbers indicate that dysploidy is likely present in the genus. Yamazaki (1993) reported chromosome numbers for four species; however, there is no indication regarding how these counts were determined. Species include C. kochiana Makino $(2 n=$ $34), C$. formosana Rolfe $(2 n=36), C$. japonica $(2 n=32,36)$, and $C$. dichotoma Raeusch. $(2 n=$ 36). Similarly, Harley et al. (2004) reported the generic chromosome complement of $\mathrm{Cal}$ licarpa as $2 n=16$ or 18 with no reference, although it is likely that the source was Darlington and Wylie (1956).

There has been a lack of reports in recent years for chromosome numbers of Callicarpa. 
The Index to Plant Chromosome Numbers online database (Goldblatt and Johnson, 1979) publishes newly reported chromosome counts from 1979 onward and does not contain any counts for Callicarpa. Nearly 50 years ago, Santamour (1965) called for a "critical cytotaxonomic treatment study of a large number of species [of Callicarpa]." The objective of the current research was to document chromosome number and genome size of Callicarpa species to add to the available information on the genus.

\section{Materials and Methods}

Plant material. Sixteen taxa representing 14 species were maintained in containers at the University of Georgia, Tifton Campus. Plants were grown in 2.4-L or 11.4-L containers filled with substrate containing 8 pine bark: 1 sand amended with $0.91 \mathrm{~kg} \cdot \mathrm{m}^{-3}$ dolomitic lime and $0.45 \mathrm{~kg} \cdot \mathrm{m}^{-3}$ Micromax (The Scotts Co., Marysville, $\mathrm{OH}$ ) and topdressed with $15 \mathrm{~g}(2.4 \mathrm{~L})$ or $45 \mathrm{~g}$ (11.4 L) of Osmocote Plus 15-4.0-9.1 (The Scotts Co.). The 16 taxa that were studied along with their accession numbers that we assigned are found in Table 2 .

Genome sizing. Leaf tissue preparation and diamidino phenyl indole (DAPI) nuclei staining were performed according to Contreras et al. (2009). Pisum sativum L. 'Ctirad', with a genome size of $8.76 \mathrm{pg}$ (Greilhuber et al., 2007), was used as an internal standard to calculate holoploid genome size $\{2 \mathrm{C}$ DNA content of sample [pg] $=8.76 \mathrm{pg} \times[$ mean DNA fluorescence (MRF) sample/MRF standard]\}. Monoploid (1Cx-value; Greilhuber et al., 2005) genome sizes were calculated by dividing the holoploid $2 \mathrm{C}$ value by the number of chromosome sets. Analysis was conducted using a Partec PA II flow cytometer (Partec, Münster, Germany). Three replicates were used for each taxon. Mean holoploid DNA content for each species was subjected to analysis of variance (ANOVA) and means were separated based on least significant difference (LSD) ( $\alpha=$ 0.05) using SAS (PROC ANOVA, SAS 9.1.3; SAS Institute Inc., Cary, NC). Data for CV \% are presented as means $\pm \mathrm{SE}$.

Cytological analysis. Plants were grown in containers as described previously. Containers were placed in trays filled with vermiculite and roots were allowed to grow out of the containers into vermiculite for collection. Collection of roots and cytological analysis were performed according to Contreras et al. (2009). Chromosomes were stained using modified carbol fuchsin and 10 to 20 cells were counted for each taxon.

\section{Results and Discussion}

Holoploid genome size estimates ranged from $1.34 \mathrm{pg}$ to $3.48 \mathrm{pg}$ with a mean of 1.74 pg (Table 2). Little variation in holoploid genome size was observed with the exception of C. salicifolia and C. macrophylla GEN090081, which had approximately twice the DNA content of the mean of other samples included in the study (Table 2). Mean separation using LSD $(\alpha=0.05)$ showed there were

Table 1. Previously reported chromosome numbers in Callicarpa.

\begin{tabular}{lcl}
\hline Taxon & Chromosome no. & \multicolumn{1}{c}{ Citation } \\
\hline C. acuminata & $2 n=34$ & Mehra and Bawa, 1969 \\
C. americana & $2 n=36$ & Lewis, 1961; Santamour, 1965 \\
C. formosana & $2 n=36$ & Chuang et al., 1963 \\
C. glabra & $2 n=32,34$ & Ono, 1975 \\
C. japonica & $2 n=32$ & Sugiura, 1936 \\
C. japonica & $2 n=36$ & Santamour, 1965 \\
C. loureiroi Hook. \& Arn. & $2 n=34$ & Chuang et al., 1963 \\
C. macrophylla & $2 n=32,34$ & Sharma and Mukhopadhyay, 1963 \\
C. nishimurae Koidz. & $2 n=34$ & Ono, 1975 \\
C. psilocalyx & $2 n=34$ & Mehra and Bawa, 1969 \\
C. subpubescens & $2 n=30,34$ & Ono, 1975 \\
C. tomentosa & $2 n=68,85$ & Mehra and Bawa, 1969 \\
\hline
\end{tabular}

Table 2. Genome sizes calculated using flow cytometry on diamidino phenyl indole (DAPI)-stained nuclei and chromosome numbers counted using light microscopy of Callicarpa spp. maintained at the University of Georgia, Tifton Campus.

\begin{tabular}{|c|c|c|c|c|c|c|}
\hline Taxon & Accession & $\begin{array}{l}\text { 2C genome } \\
\text { size }(\mathrm{pg})^{\mathrm{z}}\end{array}$ & $\begin{array}{c}1 \mathrm{C} \times \text { genome } \\
\text { size }(\mathrm{pg})^{\mathrm{y}}\end{array}$ & $\mathrm{CV} \%$ & $\begin{array}{l}\text { Chrom. } \\
\text { no. }{ }^{x}\end{array}$ & Ploidy \\
\hline C. acuminata & GEN08-0041 & $1.54 \mathrm{~b}^{\mathrm{w}}$ & 0.77 & $6.75 \pm 0.76$ & - & $2 x$ \\
\hline C. americana 'Lactea' & - & $1.56 \mathrm{~b}$ & 0.78 & $6.08 \pm 0.50$ & - & $2 x$ \\
\hline C. cathayana & GEN08-0030 & $1.52 \mathrm{~b}$ & 0.76 & $5.94 \pm 0.15$ & - & $2 x$ \\
\hline C. chejuensis & GEN08-0040 & $1.44 \mathrm{~b}$ & 0.72 & $6.13 \pm 0.46$ & $2 n=34$ & $2 x$ \\
\hline C. ferruginea & GEN08-0038 & $1.62 \mathrm{~b}$ & 0.81 & $6.46 \pm 0.39$ & - & $2 x$ \\
\hline C. formosana & GEN08-0029 & $1.34 \mathrm{~b}$ & 0.67 & $4.86 \pm 0.36$ & - & $2 x$ \\
\hline C. japonica & GEN08-0034 & $1.45 \mathrm{~b}$ & 0.72 & $4.75 \pm 0.36$ & - & $2 x$ \\
\hline $\begin{array}{l}\text { C. japonica } \\
\text { 'Leucocarpa' }\end{array}$ & - & $1.52 \mathrm{~b}$ & 0.76 & $7.02 \pm 0.80$ & $2 n=34$ & $2 x$ \\
\hline C. kwangtungensis & GEN08-0035 & $1.64 \mathrm{~b}$ & 0.82 & $5.93 \pm 0.31$ & - & $2 x$ \\
\hline C. longissima & GEN08-0042 & $1.63 \mathrm{~b}$ & 0.82 & $5.82 \pm 0.68$ & $2 n=34$ & $2 x$ \\
\hline C. macrophylla & GEN08-0039 & $1.76 \mathrm{~b}$ & 0.88 & $5.01 \pm 0.44$ & - & $2 x$ \\
\hline C. macrophylla & GEN09-0081 & $3.48 \mathrm{a}$ & 0.87 & $8.67 \pm 1.59$ & $2 n=68$ & $4 x$ \\
\hline C. rubella & GEN08-0033 & $1.39 \mathrm{~b}$ & 0.69 & $7.21 \pm 0.52$ & $2 n=34$ & $2 x$ \\
\hline C. salicifolia & GEN08-0031 & $3.11 \mathrm{a}$ & 0.78 & $4.45 \pm 0.34$ & $2 n=68$ & $4 x$ \\
\hline C. shikokiana & GEN08-0032 & $1.44 \mathrm{~b}$ & 0.72 & $5.35 \pm 0.24$ & - & $2 x$ \\
\hline C. $\times$ tosaensis & GEN08-0037 & $1.42 \mathrm{~b}$ & 0.71 & $5.26 \pm 0.09$ & - & $2 x$ \\
\hline
\end{tabular}

${ }^{\mathrm{z} H o l o p l o i d ~ g e n o m e ~ s i z e ; ~ d e t e r m i n e d ~ u s i n g ~ P i s u m ~ s a t i v u m ~ ' C t i r a d ' ~ a s ~ a n ~ i n t e r n a l ~ s t a n d a r d ~ w i t h ~ k n o w n ~}$ genome size of $8.76 \mathrm{pg} ; \mathrm{n}=3$. Calculated using the formula: $2 \mathrm{C}$ DNA content of sample $=8.76 \times[\mathrm{mean}$ relative fluorescence of sample (MRF)/MRF standard].

${ }^{\mathrm{y}}$ Monoploid genome size; calculated as above and divided by the number of sets of chromosomes.

${ }^{\mathrm{x}}$ Chromosome counts performed on mitotic spreads of meristematic root tip cells prepared and stained using modified carbol fuchsin technique (Kao, 1975); counted using light microscopy at $\times 1000$ magnification.

${ }^{\text {w}}$ Means within column followed by the same letter are not different based on least significant difference $\alpha=0.05$.

no significant differences among diploid and tetraploid samples, respectively (Table 2). Monoploid genome sizes were also calculated and ranged from $0.67 \mathrm{pg}$ to $0.88 \mathrm{pg}$ with a mean of $0.77 \mathrm{pg}$. The lack of variation in monoploid genome size indicates that there is not a large difference in chromosome size among the taxa evaluated. This conclusion is based on the assumption that all species have the same base chromosome number $(x=17)$, discussed subsequently. Furthermore, all species subjected to genome size estimation were diploid with the exception of $C$. salicifolia and one accession of C. macrophylla.

As indicated, there are no published estimates for genome size for Callicarpa; however, Bennett and Leitch (2005) reported 21 estimates for genome sizes in Lamiaceae. These monoploid genome size estimates ranged from $0.33 \mathrm{pg}$ to $5.65 \mathrm{pg}$ with a mean of $1.56 \mathrm{pg}$. The current estimates for Callicarpa fall within the range of values previously reported for the family and provide the first report of cytological or genome information for a number of species, including
C. cathayana Chang., C. chejuensis, C. ferruginea Sw., C. kwangtungensis Chun, C. longissima, C. rubella, C. shikokiana Makino, and C. ×tosaensis Makino. Callicarpa $\times$ tosaensis is reported to be a hybrid of C. kochiana and C. japonica (Yamanaka, 1988). All of these species are native to Southeast Asia except $C$. ferruginea, which is of Cuban origin. This report is the first account of genome information from the New World center of genetic diversity. The current study evaluated nuclei stained with DAPI, which binds preferentially to AT-rich regions of DNA as opposed to a DNA intercalator such as propidium iodide. Propidium iodide is the recommended fluorochrome for precise genome size estimation (Leitch and Bennett, 2007); however, DAPI is acceptable for relative estimation and ploidy determination as used in the current study (Parris et al., 2010).

Chromosome counts are reported for six species (Table 2; Fig. 1A-F). Four samples appear to be diploid with the chromosome complement $2 n=2 x=34:$ C. chejuensis, C. japonica 'Leucocarpa', C. longissima, and 

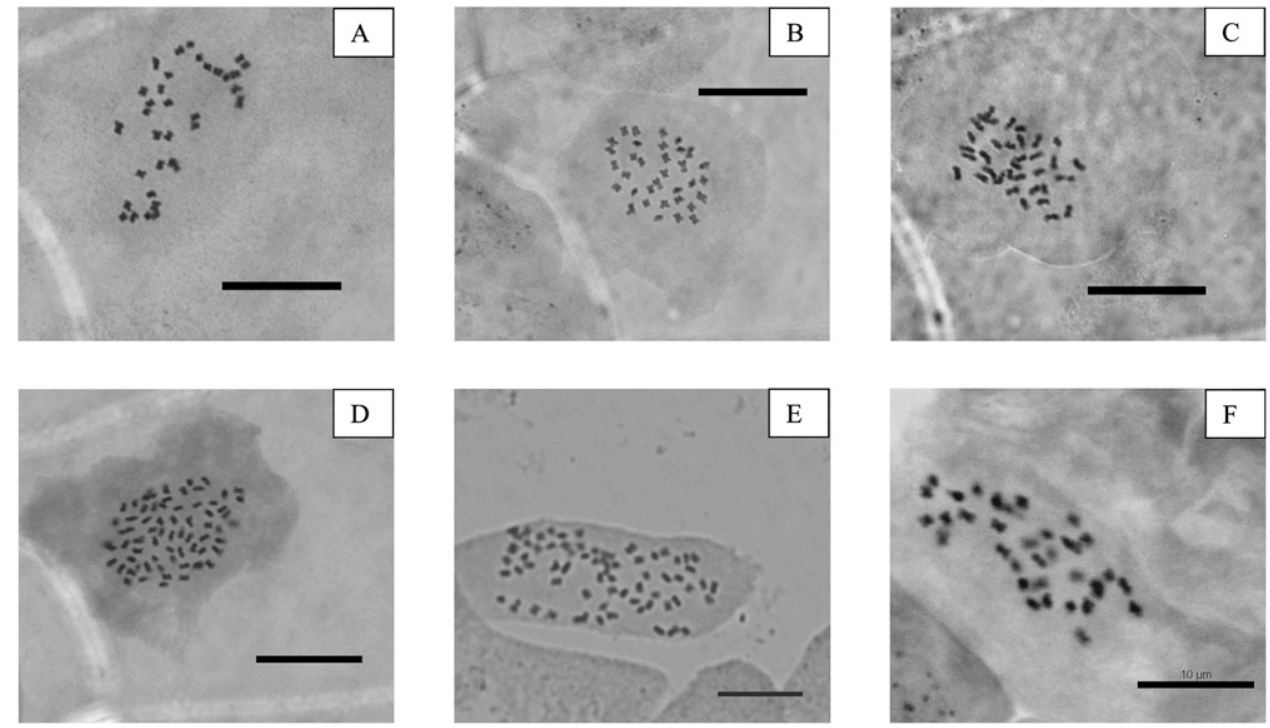

Fig. 1. Photomicrographs of chromosome spreads prepared using meristematic root tips of (A) Callicarpa chejuensis, (B) C. japonica 'Leucocarpa', (C) C. rubella, (D) C. salicifolia, (E) C. macrophylla GEN09-0081, and (F) C. longissima. Scale bar $10 \mu \mathrm{m}$.

C. rubella. Callicarpa macrophylla GEN090081 and $C$. salicifolia both had twice the number of chromosomes and were interpreted as tetraploids $(2 n=4 x=68)$. Chromosome counts were compared with genome size estimates and used to infer the ploidy of species not analyzed cytologically (Table 2). The current counts are consistent with the findings of Mehra and Bawa (1969) and Sharma and Mukhopadhyay (1963) who reported $x=17$ for C. tomentosa, C. psilocalyx C.B. Clarke, C. acuminata Roxb., and C. macrophylla (Table 1). On the other hand, base chromosome number in Callicarpa has also been reported as $x=8$ or 9 (Lewis, 1961; Santamour, 1965). The erroneous citation of Sugiura (1936) is the only report of Callicarpa below $2 n=32$. It is likely that $C$. japonica, C. americana, and C. dichotoma are diploid, not tetraploid as previously reported (Lewis, 1961; Santamour, 1965); however, as a result of the occurrence of multiple ploidy levels in other species, it may be possible that there are populations with chromosome complements of $2 n=16$ or $2 n=18$.

The current study reported two tetraploid species (C. macrophylla and C. salicifolia). Two accessions of $C$. macrophylla were included, one diploid determined by genome size estimation and one tetraploid determined by genome size estimation and confirmed by chromosome counts. Sharma and Mukhopadhyay (1963) previously reported a diploid count of $2 n=34$ for $C$. macrophylla as well as a variant that was an apparent nullisomic aneuploid $(2 n=32)$. Previous accounts of chromosome numbers of $C$. acuminata, C. psilocalyx, and $C$. tomentosa reported $x=17$; furthermore, three collection sites of $C$. tomentosa were assessed and two were reported as octoploid $(2 n=136)$ and one was decaploid $(2 n=170)$ (Mehra and Bawa, 1969). The current research supports the report of Mehra and Bawa (1969) regarding the presence of a polyploid series in Callicarpa. Although it is not completely clear, dysploidy, not just isolated cases of aneuploidy, appears to be present in Callicapra. Dysploidy is the stepwise loss of chromosomes within a genus and its occurrence in Callicarpa is supported by the fact that Chuang et al., (1963), Lewis (1961), Ono (1975), Santamour (1965), and Sugiura (1936) all reported chromosome counts in the genus that can be interpreted as varying from $x=17$ and include $x=15,16$, and 18. Multiple base chromosome numbers have been reported elsewhere. Lantana L. is based on at least two base chromosome numbers ( $x=11$ and 12) and polyploid series are found in both basic lines (Sanders, 1987).

All of the species included in the current study except $C$. americana 'Lactea', $C$. $a c u$ minata, and $C$. ferruginea have similar distributions in Asia (Shou-liang and Gilbert, 1994) indicating that the development of their current base chromosome number likely took place before their divergence. If the reports of Santamour (1965) and Sugiura (1936) are accurate and combined with the current report, then $C$. japonica also has aneuploid populations. Only a single genotype of $C$. japonica was used in the current research, so it is not possible to determine if previous reports are incorrect or if there are populations with different chromosome numbers. Lewis (1961) and Santamour (1965) both report the chromosome number of $C$. americana as $2 n=36$. Because the distribution of $C$. americana is separated from other species that have been reported, it is likely that its genome evolution and polyploidization/diploidization occurred independently. Similarly, Ono (1975) reported aneuploidy in two of three species found on the Bonin Islands. These species have evolved in isolation, because the islands have never been connected to any landmass (see Asami, 1970; Kawakubo, 1990).

This research was initiated to support an applied breeding program with the goal of com- bining novel phenotypes such as the purple foliage of $C$. kwangtungensis with adaptability of American beautyberry. Germplasm was assembled through a combination of availability of material and horticultural interest. Over 500 interspecific crosses were made in 2008 in attempts to cross $C$. americana with six species, including C. acuminata, C. cathayana, C. formosana, $C$. japonica 'Leucocarpa', $C$. kwangtungensis, and $C$. longissima (data not shown). Fruit and seed were recovered from most crosses, but no seedlings were recovered indicating that post-fertilization barriers are present. To obtain hybrid progeny from these crosses, it may be necessary to use techniques such as embryo rescue, embryo culture, ovary culture, ovule culture, etc. (Kush and Brar, 1992). Our hypothesis was that different base chromosome numbers between species was the basis for apparent incompatibility. Perhaps this is a contributing factor to the lack of success in crosses between $C$. americana $(2 n=36)$ and $C$. acuminata or $C$. japonica 'Leucocarpa', which both have the chromosome complement $2 n=34$. Alternatively, $C$. americana and $C$. formosana are both reported to have a chromosome complement of $2 n=36$, but reciprocal crosses between these species were also unsuccessful. These results suggest other incompatibility issues are present, which prevent hybridization between these species. There are no reports of attempts to make interploid crosses in Callicarpa; however, based on our crossing efforts, it seems unlikely that interspecific/interploid crosses will be successful.

The current research provides genome size estimates using flow cytometry on DAPIstained nuclei for Callicarpa. Genome sizes all lie within the range of previous reports for Lamiaceae. Chromosome numbers are also reported for six species and the base chromosome number of $x=17$ is common for all. Two tetraploid species are reported. The current research agrees with some of the previous reports on the base chromosome number and presence 
of a polyploid series in Callicarpa. Polyploidy within and among species suggests that polyploidization events have occurred in the genus. Although the current report adds to the available cytological information for Callicarpa, it also raises a question regarding correct chromosome complement of species, specifically $C$. japonica. It is clear that polyploidy and dysploidy have played a role in the evolution of genus Callicarpa but to completely understand the role of these phenomena, the comprehensive cytotaxonomic treatment called for by Santamour remains necessary.

\section{Literature Cited}

Asami, S. 1970. Topography and geology in the Bonin Islands, p. 91-108. In: Tuyama, T. and S. Asami (eds.). The nature in the Bonin Islands. Hirokawa, Tokyo, Japan. [in Japanese].

Bennett, M.D., P. Bhandol, and I.J. Leitch. 2000. Nuclear DNA amounts in angiosperms and their modern uses-807 new estimates. Ann. Bot. 86:859-909.

Bennett, M.D. and I.J. Leitch. 1995. Nuclear DNA amounts in angiosperms. Ann. Bot. (Lond.) 76: 113-176.

Bennett, M.D. and I.J. Leitch. 1997. Nuclear DNA amounts in angiosperms - 583 new estimates. Ann. Bot. (Lond.) 80:169-196.

Bennett, M.D. and I.J. Leitch. 2005. Plant DNA Cvalues database, release 4.0. Royal Botanic Gardens, Kew, U.K. Oct. 2005. 13 Oct. 2009. $<$ http://data.kew.org/cvalues/>.

Bir, R.E. and J.L. Conner. 1997. Field growing florist branches. Proc. Southern Nursery Assn. Res. Conf. 42:178-180.

Bramley, G.L.C. 2009. The genus Callicarpa (Lamiaceae) on Borneo. Bot. J. Linn. Soc. 159:416455.

Cantino, P. 1992. Towards a phylogenetic classfication of the Labiatae, p. 27-37. In: Harley, R.M. and T. Reynolds (eds.). Advances in Labiatae science. Royal Botanic Gardens, Kew, U.K.

Cantrell, C.L., J.A. Klun, C.T. Bryson, M. Kobaisy, and S.O. Duke. 2005. Isolation and identification of mosquito bite deterrent terpenoids from leaves of American (Callicarpa americana) and Japanese (Callicarpa japonica) beautyberry. J. Agr. Food Chem. 53:5948-5953.

Chuang, T.I., C.Y. Chao, W.W.L. Hu, and S.C. Kwan. 1963. Chromosome numbers of the vascular plants of Taiwan I. Taiwania 1:51-66.

Contreras, R.N., J.M. Ruter, and W.W. Hanna. 2009. An oryzalin-induced autoallooctoploid of Hibiscus acetosella 'Panama Red'. J. Amer. Soc. Hort. Sci. 134:1-7.
Cruz-Ortega, R., G. Ayala-Cordero, and A.L. Anaya. 2002. Allelochemical stress produced by the aqueous leachate of Callicarpa acuminata: Effects on roots of bean, maize, and tomato. Physiol. Plant. 116:20-27.

Darlington, C.D. and A.P. Wylie. 1956. Chromosome atlas of flowering plants. Hafner, New York, NY.

Fehr, W.R. 1991. Polyploidy, p. 59-65. In: Fehr, W.R. (ed.). Principles of cultivar development: Theory and technique. Vol. 1. Macmillan, New York, NY.

Goldblatt, P. 2007. The Index to Plant Chromosome Numbers-Past and future. Taxon 56:984986.

Goldblatt, P. and D.E. Johnson (eds.). 1979. Index to Plant Chromosome Numbers. Missouri Botanical Garden, St. Louis, MO. 15 Oct. 2009. <http:// mobot.mobot.org/W3T/Search/ipcn.html>.

Greer, L. and J.M. Dole. 2009. Woody cut stems for growers and florists: How to produce and use branches for flowers, and fruit, and foliage. Timber Press, Portland, OR.

Gregory, T.R. 2005. The C-value enigma in plants and animals: A review of parallels and an appeal for partnership. Ann. Bot. (Lond.) 95:133-146.

Greilhuber, J., J. Dolezel, M.A. Lysak, and M.D. Bennett. 2005. The origin, evolution and proposed stabilization of the terms 'genome size' and ' $\mathrm{C}$-value' to describe nuclear DNA contents. Ann. Bot. (Lond.) 95:255-260.

Greilhuber, J., E.M. Temsch, and J.C.M. Loureiro. 2007. Nuclear DNA content measurement, $\mathrm{p}$. 67-101. In: Doležel, J., J. Greilhuber, and J. Suda (eds.). Flow cytometry with plant cells. Wiley-VCH, Weinheim, Germany.

Guerra, M. 2008. Chromosome numbers in plant cytotaxonomy: Concepts and implications. Cytogenet. Genome Res. 120:339-350.

Harley, R.M., S. Atkins, A.L. Budantsev, P.D. Cantino, B.J. Conn, R. Grayer, M.M. Harley, R.D.E. Kok, T. Krestovskaja, R. Morales, A.J. Paton, O. Ryding, and T. Upson. 2004. Labiatae, p. 167-275. In: Kubitzki, K. (ed.). The families and genera of vascular plants. Vol. VI. Springer-Verlag, Berlin, Germany.

Kao, K.N. 1975. A nuclear staining method for plan protoplasts, p. 60-62. In: Gamborg, O.L. and L.R. Wetter (eds.). Plant tissue culture methods. National Research Council of Canada, Ottawa, Ontario.

Kawakubo, N. 1990. Dioecism of the genus Callicarpa (Verbenaceae) in the Bonin (Ogasawara) Islands. Bot. Mag. Tokyo 103:57-66.

Kush, G.S. and D.S. Brar. 1992. Overcoming the barriers in hybridization, p. 47-61. In: Kalloo, G. and J.B. Chowdhury (eds.). Distant hybridization of crop plants. (Monographs on theoretical and applied genetics; vol. 16). Springer-Verlag, New York, NY.
Leitch, I.J. and M.D. Bennett. 2007. Genome size and its uses: The impact of flow cytometry, $\mathrm{p}$. 153-176. In: Doležel, J., J. Greilhuber, and J. Suda (eds.). Flow cytometry with plant cells. Wiley-VCH, Weinheim, Germany.

Levin, D.A. and A.C. Wilson. 1976. Rates of evolution in seed plants: Net increase in diversity of chromosome numbers and species numbers through time. Proc. Natl. Acad. Sci. USA 73:2086-2090.

Lewis, W.H. 1961. Chromosome numbers for five American species of Callicarpa, Lantana, and Phyla (Verbenaceae). Southwest. Nat. 6:47-48.

Mehra, P.N. and K.S. Bawa. 1969. Chromosomal evolution in tropical hardwoods. Evolution 23: 466-481.

Mehra, P.N. and K.S. Bawa. 1972. Cytogenetical evolution of hardwoods. Nucleus 15:64-83.

Moldenke, H.N. 1936. A monograph of the genus Callicarpa as it occurs in America and in cultivation. Feddes Repert. 39:288-317.

Ono, M. 1975. Chromosome numbers of some endemic species of the Bonin Islands I. Bot. Mag. Tokyo 88:323-328.

Parris, J.K., T.G. Ranney, H.T. Knap, and W.V. Baird. 2010. Ploidy levels, relative genome sizes, and base pair composition in Magnolia. J. Amer. Soc. Hort. Sci. 135:533-547.

Sanders, R.W. 1987. Taxonomic significance of chromosome observations in Caribbean species of Lantana (Verbenaceae). Amer. J. Bot. 74:914920.

Santamour, F.S., Jr. 1965. Cytological notes: Introduction and I. Callicarpa. [sic]. Morris Arboretum Bul. 16:51-52.

Sharma, A.K. and S. Mukhopadhyay. 1963. Cytotaxonomic investigation with the aid of an improved method on the family Verbenaceae with special reference to the lines of evolution. J. Genet. 58:358-386.

Shou-liang, C. and M.G. Gilbert. 1994. Callicarpa, p. 4-16. Zheng-yi, W. and P.H. Raven. Flora of China: Verbenaceae through Solanaceae. Vol. 17. Missouri Botanical Garden, St.Louis, MO.

Sugiura, T. 1936. Studies of the chromosome numbers in higher plants, with special reference to cytokinesis I. Cytologia (Tokyo) 7:544-595.

Tellez, M.R., F.E. Dayan, K.K. Schrader, D.E. Wedge, and S.O. Duke. 2000. Composition and some biological activities of the essential oil of Callicarpa americana (L.) [sic]. J. Agr. Food Chem. 48:3008-3012.

Yamanaka, T. 1988. On Callicarpa tosaensis Makino. J. Japanese Bot. 63:15-17.

Yamazaki, T. 1993. Verbenaceae, p. 259-271. In: Iwatsuki, K., T. Yamazaki, D.E. Boufford, and H. Ohba (eds.). Flora of Japan. Vol. IIIa. Kodansha, Tokyo, Japan. 